UDC: 364.628:37.015.3

DOI: $10.26697 /$ ijes.2019.2.31

\section{Teachers Attitudes Toward Special Need Students and Teaching Sittings Readiness in Egypt}

Assistant Professor Zizi Elsayed Ibrahim ${ }^{1}$

${ }^{1}$ Fayoum University, Egypt

\begin{abstract}
Background:

Mental disabled adolescents developed needs for having tools to face the challenges of this stage of life, main source of information and skill enhancing are the teachers who help them to figure out what life is and how to deal with daily life situations.

The aim of this study is to reveal the attitudes of teachers of mental disabled adolescents and how teachers evaluate readiness of the real teaching sittings.
\end{abstract}

\section{Methods:}

331 teachers $($ Male $=123$ or $37 \%$ and Female $=208$ or $63 \%$ ) completed the "attitudes towards mental disabled adolescents questionnaire" (Gameel, 2010) along with brief demographic form, and Individual interview to evaluate readiness for implementation conducted. Mean scores, T-test calculated to compare mean scores of teachers who are working in special needs settings $(n=142$ or $43 \%)$ with teachers who are working in general education school $(n=189$ or $57 \%)$ in overall attitudes and in the five subscales. Analysis of sitting readiness for implementation conducted.

\section{Results:}

Results show that teachers have general positive attitudes regardless of type of education type.

Type of education affect the family - teacher communication attitudes scores while no significant differences found between special education teachers and general education teachers ratings on the total or other subscales. Interview analysis show that implementation of special need education programs face challenges with teacher readiness, resources and context facilitations in the general education sittings.

\section{Conclusions:}

In spite of having positive attitudes towards, teachers still need to solve the challenges that face them in offering the most appropriate education for mental disabled adolescents.

\section{Information about the author:}

Zizi Elsayed Ibrahim - Doctor of Philosophy in Clinical Psychology, Assistant Professor, Fayoum University, Fayoum, Egypt.

Research interests: theory and practice of clinical psychology, neurodevelopmental disorders, psychology of education, special needs education; https://orcid.org/0000-0001-8329-9615.

\section{Corresponding Author:}

Zizi Elsayed Ibrahim

\section{Corresponding Author's Email:}

zss11@fayoum.edu.eg 